\title{
Fontes históricas de pesquisa qualitativa: um olhar dirigido aos cadernos escolares
}

\author{
Cleonara Maria Schwartz ${ }^{1}$, Fabiana da Silva Kauark² e Fernanda \\ Zanetti Becalli ${ }^{2}$
}

1Universidade Federal do Espírito Santo, Brasil | cleonara.schwartz@gmail.com | https://orcid.org/0000-0003-4411-2234

${ }^{2}$ Instituto Federal de Educação, Ciência e Tecnologia do Espírito Santo, Brasil | fabianak@ifes.edu.br | https://orcid.org/0000-0002-8807-931X | fernanda.becalli@ifes.edu.br | https://orcid.org/0000-0002-8628-6550

\begin{abstract}
Resumo: As pesquisas sobre alfabetização de crianças, fundamentadas teórica e metodologicamente em princípios bakhtinianos, em especial nos conceitos de enunciado, discurso dialógico, exotopia e compreensão, configuram-se como temática principal tanto do Núcleo de Estudos e Pesquisas em Alfabetização, Leitura e Escrita do Espírito Santo como do Grupo de Estudos e Pesquisas em Alfabetização Escolar. Neste texto, abordaremos, especificamente, investigações destes grupos de trabalho que se ancoram na abordagem qualitativa, assumem os delineamentos da pesquisa documental e constituem o corpus documental, reconhecido em nossos estudos como corpus discursivo, de cadernos escolares. Entendendo-os como fontes históricas de pesquisa, depositárias de discursos acerca do ensino da linguagem escrita, que oferecem indícios de práticas alfabetizadoras, elegeram-se os procedimentos de localização, de tratamento e de seleção das fontes documentais, bem como os princípios adotados pelos pesquisadores para a análise dos enunciados.
\end{abstract}

Palavras Chave: Educação; Avaliação; Cadernos escolares; Análise documental; Investigação Qualitativa.

\section{Introdução}

O Núcleo de Estudos e Pesquisas em Alfabetização, Leitura e Escrita do Espírito Santo (Nepales), sediado no Centro de Educação da Universidade Federal do Espírito Santo (Ufes), foi criado em 2006, com o objetivo de se constituir como um espaço de referência, no Estado do Espírito Santo, Brasil, para discussão teórica e metodológica no campo da alfabetização, da leitura e da escrita, organização de acervos documentais e de levantamento e sistematização de fontes e dados. Vinculados ao Núcleo estão professoras pesquisadoras da Ufes, do Instituto Federal de Educação, Ciência e Tecnologia do Espírito Santo (Ifes), das escolas estaduais e municipais de educação básica, bem como estudantes do Curso de Licenciatura em Pedagogia, do Programa de Pós-graduação em Educação (PPGE) e do Programa de Pós-graduação de Mestrado Profissional em Educação (PPGMPE), ambos da Universidade.

Decorridos dez anos, foi instituído, em parceria com o Nepales, o Grupo de Estudos e Pesquisas em Alfabetização Escolar (Gepales), cadastrado no Conselho Nacional de Desenvolvimento Científico e Tecnológico (CNPq) e sediado no Ifes campus Vila Velha. Juntamente com professoras pesquisadoras do Ifes e de escolas estaduais e municipais de educação básica, além de estudantes do Curso de Licenciatura em Pedagogia e do Programa de Pós-graduação de Mestrado Profissional em Ensino de Humanidades (PPGEH) do Ifes, o Gepales desenvolve estudos e pesquisas no campo da alfabetização, da leitura, da escrita, a partir de áreas do conhecimento ligadas às Humanidades; produz e socializa materiais didático-pedagógicos como o de Lima e Becalli (2018) e o de Ribeiro e Becalli (2019), que discutem e apresentam propostas relacionadas ao trabalho docente na alfabetização de crianças.

A produção científica que deriva do trabalho desenvolvido pelos pesquisadores, vinculados a ambos os espaços, tem como temática central a alfabetização de crianças. Trata-se de temática interdisciplinar, vinculada principalmente às áreas de Educação (em particular, os campos da Didática, do Currículo, da Formação de Professores, do Planejamento e Avaliação Educacional e da História da Educação). 
Dentre o conjunto de trabalhos produzidos, dialogaremos, neste texto, especificamente, com os seguintes: Práticas de alfabetização no município de Viana (ES) no período de 2000 a 2009 (Pinheiro, 2012); Nos cadernos escolares de um passado recente: uma história do ensino da leitura no Estado do Espírito Santo (2001-2008) (Becalli, 2013); O ensino das relações sons e letras e letras e sons no contexto da alfabetização no município de Vitória (Rizzo, 2015); Atividades de leitura de textos na alfabetização: problematizações a partir de cadernos escolares (Macedo, 2018).

Estas pesquisas foram selecionadas porque ambas se ancoram na abordagem qualitativa de investigação, assumem os delineamentos da pesquisa documental e constituem o corpus documental, reconhecido em nossos grupos como corpus discursivo, de cadernos escolares. Com destaque para o potencial teórico-metodológico dos cadernos como fontes históricas de pesquisa, compartilhamos, neste texto, os procedimentos de localização, de tratamento e de seleção das fontes documentais, bem como os princípios adotados pelos pesquisadores para a análise dos enunciados.

\section{O potencial dos cadernos escolares como fontes históricas de pesquisa}

Embora os cadernos tenham permanecido à sombra, esquecidos no fundo de gavetas, armários e/ou caixas, Mignot (2010, p.425) relata que o crescente interesse por esse objeto-memória advém de um contexto "[...] marcado por um 'giro memorialístico' que se caracteriza pela valorização da memória individual e coletiva, como uma reação ao 'presentismo"'.

Tal assertiva nos permite dizer que a multiplicidade de vozes materializadas nesses documentos possibilita o resgate da memória, porque os enunciados fixados em suas páginas funcionam como um remédio eficaz contra o esquecimento permitindo, a qualquer tempo, revisitá-los e, assim, não se esquecer de pessoas, rememorar acontecimentos, rever atividades, dialogar com diferentes escritos e diversos interlocutores em outras situações sociais.

Ao compreender os cadernos escolares como documentos, ou seja, como fontes históricas de pesquisa, torna-se fundamental clarificar que concebemos os documentos como:

[...] o resultado de uma montagem, consciente ou inconsciente, da história, da época, da sociedade que o produziram, mas também das épocas sucessivas durante as quais continuou a viver, talvez esquecido, durante as quais continuou a ser manipulado, ainda que pelo silêncio. O documento é uma coisa que fica, que dura, e o testemunho, o ensinamento (para evocar a etimologia) que ele traz devem ser em primeiro lugar analisados desmistificando-lhe o seu significado aparente. O documento é monumento. Resulta do esforço das sociedades históricas para impor ao futuro - voluntaria ou involuntariamente determinada imagem de si próprias (Le Goff, 2003, p.547-548).

$\mathrm{E}$, dentro desse raciocínio, os cadernos escolares não são documentos neutros, derivam do empenho de professoras e alunos para conferir a posteridade determinadas imagens sobre si, do modo como se veem ou gostariam de ser vistos (Le Goff, 2003). Seguindo os rastros do autor, Gvirtz e Larrondo (2008, p.43) também destacam que trabalhar "[...] o documento em si mesmo e interrogá-lo em sua imanência é o princípio metodológico que converte documento em monumento".

Orientado por esse princípio, o pesquisador não deve ter um olhar ingênuo sobre as fontes históricas de pesquisa, sendo necessário considerar as condições específicas de produção e saber interrogar os enunciados das professoras, das crianças, das propostas pedagógicas, das formas de avaliação, dos pais e/ou responsáveis etc. que foram registrados nos cadernos escolares. Viñao $(2008$, p.24) também assegura que esses "[...] objetos falam a quem souber perguntar", ou seja, os cadernos só respondem se nós, pesquisadores das ciências humanas, soubermos interrogá-los, perscrutando 0 subentendido, o não dito presentificado no dito. 
Provocados pelas leituras de diversos textos escritos por pesquisadores da área da Educação e da História da Educação (Chartier, 2002, 2007, 2007a; Gvirtz, 1997, 1999; Hébrard, 2000, 2001; Mignot, 2004, 2008, 2008a, 2008b,2010; Viñao, 2008, dentre outros) que temos nos voltado para os diferentes registros materializados nas páginas de cadernos escolares, concebendo-os como fontes históricas de pesquisa, depositárias de discursos acerca do ensino da linguagem escrita que insinuam vestígios de práticas alfabetizadoras. Compreendemos a alfabetização como:

[...] uma prática sociocultural em que as crianças, adolescentes, jovens e adultos, por meio do trabalho integrado com a produção de textos orais e escritos, a leitura, os conhecimentos sobre o sistema da língua portuguesa e as relações entre sons e letras e letras e sons, exercem a criticidade, a criatividade e a inventividade (Gontijo, 2019).

Apoiados nos estudos e diálogos estabelecidos entre estes textos e dos escritos do Círculo de Bakhtin, construímos procedimentos de localização, de tratamento e de seleção das fontes documentais que pudessem orientar os pesquisadores que elegessem os cadernos escolares como corpus discursivo.

Também foi produzido um texto com princípios norteadores para a análise dos enunciados, no qual se evidencia a preocupação do grupo em conceber as análises como elos discursivos que se interligam em uma corrente ininterrupta da comunicação discursiva que tratam da problemática estudada.

\subsection{Localização de fontes históricas de pesquisa}

Um dos primeiros desafios para os pesquisadores que elegem os cadernos escolares como fontes históricas de pesquisa dizem respeito à localização e o acesso aos cadernos escolares.

Em nossos grupos, as duas primeiras pesquisas que trabalharam com esses documentos foram as de Pinheiro (2012) e de Becalli (2013).

Naquele momento, algumas questões foram levantadas: Tais objetos são preservados? Por quem? Onde estão guardados? Há arquivos institucionais nas Superintendências Regionais, nas Secretarias Municipais de Educação e nas escolas (estaduais e municipais) para a guarda destas fontes históricas? São guardados em arquivos pessoais (residências de professoras e de alunos)?

A partir destas questões, elaboramos um protocolo de localização das fontes documentais com diferentes percursos que podem ser realizados para encontrar professoras alfabetizadoras e alunos que guardam seus cadernos escolares.

Este protocolo, apresentado no Quadro 1, também foi utilizado nas pesquisas de Rizzo (2015) e de Macedo (2018).

Importante destacar que, nas quatro pesquisas realizadas em nossos grupos, foram localizados cadernos e outros suportes de registros escolares que as professoras e as mães de alunos haviam preservado: propostas curriculares oficiais, diários de classe, planos de trabalho, projetos didáticos, roteiros de planejamento de atividades, relatórios avaliativos de desenvolvimento de atividades, relatórios de acompanhamento de alunos, folhas fotocopiadas, mimeografadas e/ou manuscritas utilizadas para atividades didáticas, atividades de avaliação valorativa, diagnósticos das hipóteses de escrita discente etc. 
Quadro 1. Protocolo de localização das fontes históricas de pesquisa

\begin{tabular}{|c|c|}
\hline N. & Diferentes percursos de localização \\
\hline 1 & $\begin{array}{l}\text { Conversar e enviar e-mails aos amigos e colegas de trabalho que possam } \\
\text { localizar professoras e/ou mães que tivessem guardados os cadernos } \\
\text { escolares. }\end{array}$ \\
\hline 2 & $\begin{array}{l}\text { Telefonar para as Superintendências Regionais de Educação e as } \\
\text { Secretarias Municipais de Educação, na tentativa de localizar professoras } \\
\text { que tivessem guardados os cadernos escolares. }\end{array}$ \\
\hline 3 & $\begin{array}{l}\text { Utilizar os espaços dos Fóruns Permanentes de Alfabetização, Leitura e } \\
\text { Escrita do Espírito Santo (Fopales), para conversar pessoalmente com os } \\
\text { representantes das Secretarias Municipais e Estadual de Educação, os } \\
\text { professores alfabetizadores e demais pessoas que participaram para } \\
\text { solicitar apoio na busca dos cadernos escolares. }\end{array}$ \\
\hline 4 & $\begin{array}{l}\text { Telefonar para as funcionárias representantes das Secretarias de Educação } \\
\text { e agendar visitas aos municípios. }\end{array}$ \\
\hline 5 & $\begin{array}{l}\text { Visitar as Secretarias Municipais e a Superintendência, com a finalidade de } \\
\text { receber indicações de escolas em que podem localizar as referidas } \\
\text { professoras. }\end{array}$ \\
\hline 6 & $\begin{array}{l}\text { Visitar às escolas estaduais e municipais para conversar com as professoras } \\
\text { alfabetizadoras e ter acesso aos cadernos escolares. }\end{array}$ \\
\hline 7 & $\begin{array}{l}\text { Visitar às residências das professoras para ter acesso aos cadernos } \\
\text { escolares. }\end{array}$ \\
\hline
\end{tabular}

Importante ressaltar que nas visitas as quarenta Secretarias Municipais de Educação e a uma Superintendência Regional de Educação, Becalli (2013) constatou que não existem, no Estado do Espírito Santo, políticas públicas de preservação da documentação escolar, tendo em vista que nenhum dos 41 órgãos visitados possuía arquivos destinados a guardar documentos produzidos cotidianamente nos fazeres docentes e discentes. Nas escolas visitadas, os arquivos se referiam exclusivamente aos das secretarias, destinados a preservar documentos tidos como oficiais. Essa constatação apontou para a necessidade de refletirmos sobre a organização de arquivos institucionais destinados a guardar e tornar públicos documentos de naturezas díspares, acumulados ao longo da história das instituições escolares, visando preservar uma memória da educação espíritosantense e "[...] tornar vivo o que, pela passagem do tempo, deveria ser consumido, esquecido, destruído, virado lixo" (Mignot \& Cunha, 2006, p.41).

\subsection{Tratamento dado às fontes históricas de pesquisa}

Apesar de no início os pesquisadores terem dificuldades de localizar os cadernos e demais suportes de registros escolares, ao trabalhar com os diferentes percursos elencados no protocolo de localização das fontes documentais, encontraram um número expressivo de fontes documentais e se depararam com as seguintes indagações:

- Que tipo de fontes históricas de pesquisa foi possível reunir?

- Foram produzidas por quais sujeitos?

- Qual critério de exploração das fontes utilizaria?

- Como organizar essa diversidade de materiais?

Buscando orientar o tratamento dado às fontes foi elaborado o protocolo que se apresenta no Quadro 2: 
Quadro 2. Protocolo de tratamento dado às das fontes históricas de pesquisa

\begin{tabular}{|c|c|c|}
\hline N. & $\begin{array}{l}\text { Tratamento dados às fontes } \\
\text { históricas de pesquisa }\end{array}$ & Objetivo \\
\hline 1 & $\begin{array}{l}\text { Digitalização dos cadernos e } \\
\text { suportes de registros escolares. }\end{array}$ & $\begin{array}{l}\text { Constituir um banco de dados digitais, } \\
\text { permitindo preservar as fontes e } \\
\text { desencadear estudos e pesquisas } \\
\text { posteriores. }\end{array}$ \\
\hline 2 & Distribuição por localidade. & $\begin{array}{l}\text { Mapear a procedência dos documentos que } \\
\text { compõem o corpus discursivo. }\end{array}$ \\
\hline 3 & Distribuição por ano letivo. & $\begin{array}{l}\text { Identificar o período histórico coberto pelos } \\
\text { documentos. }\end{array}$ \\
\hline 3 & & $\begin{array}{l}\text { Agrupar os documentos em ordem } \\
\text { cronológica crescente. }\end{array}$ \\
\hline 4 & Distribuição por série/ano. & $\begin{array}{l}\text { Identificar as séries/anos coberto pelos } \\
\text { documentos. }\end{array}$ \\
\hline 5 & Leitura exploratória. & $\begin{array}{l}\text { Familiarizar com as fontes e com os tipos de } \\
\text { atividades. }\end{array}$ \\
\hline \multirow{2}{*}{6} & Ficha individual. & $\begin{array}{l}\text { Reunir os cadernos de uma mesma } \\
\text { série/ano e de uma mesma professora ou } \\
\text { aluno numerando sequencialmente. }\end{array}$ \\
\hline & & $\begin{array}{l}\text { Reunir os cadernos de uma mesma } \\
\text { série/ano, mas de professoras ou alunos } \\
\text { diferentes, pelo primeiro nome dos sujeitos. }\end{array}$ \\
\hline
\end{tabular}

Para o preenchimento desta ficha individual, os seguintes dados referentes a identificação dos cadernos docentes e discentes deveriam ser preenchidos: foto da capa do caderno, número de identificação, década, ano letivo, série/ano, professora ou aluno, escola, município, estado, período de registro de aulas, quantidade total de páginas, quantidade de páginas utilizadas, quantidade de páginas em branco, quantidade de páginas arrancadas.

\subsection{Seleção das fontes históricas de pesquisa}

Outro desafio para os pesquisadores que elegem os cadernos escolares como fontes históricas de pesquisa se relacionam à seleção das fontes para a análise, pois a depender da quantidade localizada - por exemplo, Becalli (2013) localizou 2.113 documentos, debruçar-se sobre todos os documentos explorando, lendo, revisando e analisando, atividade por atividade, exige uma amplitude que extrapola o bom senso e o período de tempo disponível para a realização da pesquisa. Nesse sentido, entendemos que os critérios de seleção devem ser guiados pelos objetivos da pesquisa.

Uma possibilidade discutida nos encontros dos grupos e construída para orientar a seleção das fontes foi um Quadro dividido por: 
a) categorias de registros (registros escritos por profissionais das Secretarias de Educação, registros escritos por professoras, registros escritos por docentes e discentes, registros fotográficos, registros orais etc.);

b) tipos de fontes (propostas curriculares, livro de memórias, relatos autobiográficos, cadernos de registros docentes, roteiros de planejamentos, projetos, rotina semanal, sequências didáticas, diários de classe, lista de material escolar, pautas e/ou atas de reunião de pais, relatórios avaliativos dos projetos, relatórios de acompanhamento dos alunos, agenda escolar, atividades avaliativas, atividades em formato de livro, cadernos de registros discentes, folhas fotocopiadas, mimeografadas e/ou manuscritas, diagnósticos das hipóteses conceituais de escritas, pastas com registros fotográficos de atividades, arquivo digital de músicas infantis etc.);

c) critérios de exploração (discursos acerca da organização do trabalho com a linguagem escrita, discursos acerca da época em as professoras que foram alfabetizadas, discursos acerca da organização do trabalho com a linguagem escrita, discursos acerca da frequência de alunos, dos conteúdos ministrados e das avaliações, discursos acerca dos materiais a serem utilizados pelos alunos, discursos acerca de questões que foram tratados com pais e/ou responsáveis dos alunos, discursos acerca do desenvolvimento de projetos didáticos, discursos acerca do desenvolvimento cognitivo discente, discursos acerca de compromissos diários, discursos acerca de avaliações, discursos acerca das hipóteses de escrita infantil etc.); e,

d) quantidades.

Outra possibilidade para orientar a seleção das fontes consiste no mapeamento e categorização todas as atividades materializadas no conjunto de suportes de registros da escrita escolar com o número de vezes em que aparecem ao longo do período letivo registrado. Em nossas pesquisas, a categorização das atividades foi sendo construída a partir do que os registros docentes e discentes diziam, por conseguinte, não elencamos uma relação de possíveis atividades a serem encontradas nos referidos documentos $e$ fomos apenas constatar a existência (ou não) delas.

\subsection{Princípios norteadores da análise dos dados}

A análise dialógica dos enunciados materializados nos cadernos e demais suportes de registros escolares fundamenta-se na perspectiva bakhtiniana de linguagem como aporte teórico-metodológico.

Nessa abordagem, entende-se que os sujeitos, ao se relacionarem por meio da linguagem nas diferentes atividades humanas, produzem enunciados, isto é, unidades da comunicação discursiva que se dirigem a interlocutores reais e só podem ser compreendidas no seu todo, uma vez que um mesmo enunciado pode produzir sentidos diferentes, dependendo da situação de enunciação particular e do contexto histórico, cultural, social, político, econômico etc. em que foi produzido.

Lembrando que, quando nos referimos aos enunciados, estamos nos referindo aos textos. Bakhtin (2003, p.312) propõe aos estudiosos das ciências humanas uma forma outra de fazer pesquisa ao explicitar que tais ciências estudam "[...] o homem em sua especificidade humana [...]", ou seja, em seu processo de contínua expressão e criação, como um sujeito concreto, datado, expressivo, falante, produtor de textos. Diante dos enunciados produzidos pelos sujeitos, o pesquisador não deve se restringir a contemplá-los, tendo em vista que não se encontra diante de um fenômeno da natureza, um objeto mudo que precisa ser contemplado para ser descrito monologicamente, visto que "[...] o sujeito como tal não pode ser percebido e estudado como coisa porque, como sujeito e permanecendo sujeito, não pode tornar-se mudo; conseqüentemente, o conhecimento que se tem dele só pode ser dialógico" (2003, p.400, itálico no original). 
Nessa outra forma de fazer pesquisa, passa-se de uma orientação monológica na qual o pesquisador fala dos enunciados materializados nas fontes documentais, mas não com eles, para uma perspectiva dialógica em que a relação entre pesquisador e sujeitos participantes da pesquisa supõe o encontro dialógico de duas consciências (no mínimo), de dois sujeitos. Essa atitude fundamentadora da pesquisa estabelece uma relação entre sujeitos com plenos direitos à interlocução, na qual o próprio pesquisador faz "[...] parte do enunciado a ser interpretado, do texto (ou melhor, dos enunciados, dos diálogos entre estes), entra nele como um novo participante" (Bakhtin, 2003, p.329), portanto, a neutralidade das ciências exatas é impossível. O sujeito pesquisador torna-se um interlocutor atuante e responsivo dentro do processo de comunicação discursiva com os enunciados dos outros sujeitos envolvidos na pesquisa, visto que o processo da compreensão se desenvolve, primordialmente, no "[...] complexo acontecimento do encontro e da interação da palavra do outro [...]" (2003, p.380).

Trabalhar com a investigação qualitativa, assumindo os delineamentos da pesquisa documental, na perspectiva bakhtiniana de linguagem, consiste em compreender que o corpus discursivo é formado integralmente por palavras, porém não são palavras do pesquisador e sim de outros sujeitos que estão materializadas em cadernos e demais suportes de registros escolares, consequentemente, palavras alheias. Nesse contexto, a pergunta que se coloca é: como Bakhtin define a palavra alheia? Eis a resposta: "Por palavra do outro (enunciado, produção de discurso) eu entendo qualquer palavra de qualquer outra pessoa, dita ou escrita na minha própria língua ou em qualquer outra língua, ou seja, é qualquer outra palavra não minha". Depois acrescenta que a "[...] palavra do outro coloca diante do indivíduo a tarefa especial de compreendê-la [...]" (Bakhtin, 2003, p.379). Essa assertiva nos instiga a fazer outro questionamento: como analisar, em nossos trabalhos de pesquisas, palavras de docentes e de alunos que preservaram seus cadernos e outros suportes de registros escolares?

Nas ciências humanas, portanto, ao se trabalhar com palavras produzidas por sujeitos expressivos e falantes que produzem textos (orais e escritos), estamos trabalhando com enunciados produzidos num dado contexto e que estão sempre orientados para enunciados que lhes antecederam e àqueles que ainda serão produzidos, no fluxo da comunicação humana. Desse modo, os enunciados não podem ser entendidos como o primeiro nem o último, apenas como um dos elos de uma cadeia dialógica mais ampla de enunciados. Sendo a real unidade da comunicação discursiva, o enunciado pressupõe uma alternância dos sujeitos falantes, já que o "[...] falante termina o seu enunciado para passar a palavra ao outro ou dar lugar à sua compreensão ativamente responsiva" (Bakhtin, 2003, p.275). Nesse sentido, cada enunciado é pensado como uma resposta aos enunciados precedentes que "[...] os rejeita, confirma, completa, baseia-se neles, subentende-os como conhecidos, de certo modo os leva em conta" (idem, 2003, p.297). Mas, afinal, como compreendê-los?

Sobre essa questão, Bakhtin nos alerta que existe uma "[...] falsa tendência para a redução de tudo a uma única consciência, para dissolução da consciência do outro [...]" (2003, p.377), isto é, ou o pesquisador reduzir a palavra do outro às suas próprias palavras, silenciando o texto do sujeito pesquisado, não restituindo as condições de enunciações e de circulação que lhe conferem diversas produções de sentidos. Ou, o contrário, o texto do pesquisado silencia o texto do pesquisador, como se este se furtasse de qualquer afirmação que difere do que diz o pesquisado, daquilo que só seu lugar único permite ver e pensar. Conforme apontamos anteriormente, a constituição do enunciado é dialógica, por conseguinte, o fundamental na pesquisa é manter o caráter de diálogo, apontando as diferenças e as tensões entre os dois pontos de vista, a fim de que nesse "[...] encontro dialógico de duas culturas elas não se fundem nem se confundem; cada uma mantém a sua unidade e a sua integridade aberta, mas elas se enriquecem mutuamente" (Bakhtin, 2003, p. 366, itálico no original). 
Como contraposição a essa falsa tendência, Bakhtin menciona as vantagens da exotopia que implica um duplo movimento: primeiro o de "[...] compreender uma obra da mesma maneira como a compreendeu o próprio autor sem sair dos limites da compreensão dele", ou seja, do pesquisador tentar enxergar com os olhos do pesquisado e, depois, de volta ao seu lugar, "[...] utilizar sua distância temporal e cultural" (Bakhtin, 2003, p.381) para retornar à sua exterioridade, a fim de fazer intervir seu próprio olhar num dado contexto $\mathrm{e}$ as posições que ali afirma, construindo suas réplicas que quanto maiores forem, mais real e profunda será a compreensão. Podemos dizer, então, que a posição do pesquisador é uma posição de fronteira.

Ainda, de acordo com a perspectiva bakhtiniana, a compreensão está diretamente relacionada à avaliação, uma vez que o pesquisador busca compreender com sua "[...] visão de mundo já formada, de seu ponto de vista, de suas posições" (Bakhtin, 2003, p.378). Contudo, essas posições não permanecem as mesmas, já que se vinculam à ação dos enunciados dos outros que sempre trazem algo não conhecido pelo sujeito que busca compreender. E em ambos não se pode "[...] excluir a possibilidade de mudança e até de renúncia aos seus pontos de vista e posições já prontos. No ato da compreensão desenvolve-se uma luta cujo resultado é a mudança mútua e o enriquecimento" (Bakhtin, 2003, p.378). Considera-se, assim, que o pesquisador, no decorrer do processo de investigação, é um sujeito que está em processo de aprendizagem; e o sujeito participante da pesquisa que, não sendo um objeto mudo que precisa ser contemplado, também está em processo de reflexão, aprendizagem e transformações.

Considera-se, com base no que foi exposto, que a análise dos enunciados materializados nos cadernos e demais suportes de registros escolares, envolve, no primeiro momento, a leitura dialógica de todas as fontes documentais. Em segundo lugar, identificam-se os enunciados, cujo tema responde às questões de investigação, que podem ser organizados em um arquivo no formato Word. Ao se analisar as fontes documentais, procurando dialogar com os enunciados é que se percebem os pontos de encontro, as recorrências como também as diferenças. Em terceiro lugar, elege-se o critério de recorrência para evidenciar os modelos de atividades com maior frequência e, de igual modo, os outros com menor presença nos referidos documentos. Desse modo, a análise é construída por meio da identificação dos elos discursivos que se interligam em uma corrente ininterrupta da comunicação discursiva que tratam da problemática de estudo.

\section{Instaurando o Dixix conclusivo}

Estamos conscientes de que todo esse processo metodológico permitiu focalizar os cadernos e demais suportes de registros escolares como fontes históricas de pesquisa, depositárias de discursos acerca do ensino da linguagem escrita, que oferecem indícios de práticas alfabetizadoras. As investigações realizadas por pesquisadores vinculados ao Nepales (Ufes) e ao Grupo de Estudos e Pesquisas em Alfabetização Escolar (Ifes) que constituíram o corpus discursivo de suas pesquisas com cadernos escolares, possibilitou o conhecimento de:

- abordagens teóricas e metodológicas que sustentaram práticas alfabetizadoras;

- apontamentos de mudanças e/ou continuidades que se consolidaram na organização do trabalho com a linguagem escrita em classes de alfabetização;

- como políticas públicas de formação de professores alfabetizadores são aceitas e/ou renunciadas pelas professoras em seus fazeres profissionais.

Os enunciados materializados nos cadernos e analisados como um material não estático, podem significar um modo de cultivar a memória de pessoas comuns: "[...] alunos/as e professores/as que atuam anonimamente na sala de aula" (Mignot \& Cunha, 2006, p.40) e, também, de embrenhar-se no cotidiano de classes de alfabetização para compreender distintos modos de ensinar e aprender praticados ao longo da história da educação, consequentemente, adentrar em outros tempos escolares, compostos por outros professores e outros alunos, "[...] nem melhores nem piores, mas diferentes" (Mignot, 2010, p.441). 
Nesse contexto, ainda é necessário salientar que o pesquisador que elege os cadernos escolares como fontes históricas de pesquisa necessita ter clareza que nem todo o vivido em classes de alfabetização está registrado nos cadernos, por conseguinte, é necessário o cruzamento de fontes. Instauramos um dixix conclusivo neste texto com a esperança de que o processo metodológico apresentado possa contribuir para o debate de preservação dessas fontes documentais ainda esquecidas, trazendo à luz fontes históricas que guardam a memória da alfabetização de crianças. Assim, almejamos incentivar outros estudos e pesquisas com cadernos escolares alicerçados na análise dialógica do discurso.

\section{Referências}

Bakhtin, M. M. (2003) Estética da criação verbal. São Paulo: Martins Fontes.

Becalli, F. Z. (2013). Nos cadernos escolares de um passado recente: uma história do ensino da leitura no estado do Espírito Santo (2001 a 2008) (Tese de Doutorado). Universidade Federal do Espírito Santo. Espírito Santo, Brasil.

Chartier, A-M. (2002). Um dispositivo sem autor: cadernos e fichários na escola primária. Revista Brasileira de História da Educação, 2(3), 9-26.

Chartier, A-M. (2007). Exercícios escritos e cadernos de alunos: reflexões sobre práticas de longa duração. In Chartier, A-M (Org.), Práticas de leitura e escrita. História e atualidade (pp. 5169). Belo Horizonte: Autêntica.

Chartier, A-M. (2007a). Os cadernos escolares: organizar os saberes, escrevendo-os. Revista de Educação Pública, 16(32), 13-34.

Gontijo, C. M. M. (2019). Conceito de alfabetização e formação de docentes. In M. S. Góes, J. S. C. Antunes and D. M. V. Costa (Org.), Experiências de formação de professores alfabetizadores (pp. 15-46). São Paulo: Pedro \& João Editores.

Gvirtz, S. (1997). Del curriculum prescripto al curriculum enseñado: uma mirada a los cuadernos de clase. Buenos Aires: Aique.

Gvirtz, S. (1999). El discurso escolar através de los cuadernos de clase. Buenos Aires: Eudeba.

Gvirtz, S., \& Larrondo, M. (2008). Os cadernos de classe como fonte primária de pesquisa: alcances e limites teóricos e metodológicos para sua abordagem. In A. C. V. Mignot (Org.), Cadernos à vista: escola, memória e cultura escrita (pp. 35-48). Rio de Janeiro: EdUERJ.

Hébrard, J. (2000). Por uma bibliografia material das escrituras ordinárias: a escritura pessoal e seus suportes. In A. C. V. Mignot, M. H. C. Bastos and M. T. S. Cunha (Orgs.), Refúgios do eu: educação, história e escrita autobiográfica (pp. 29-61). Florianópolis: Mulheres.

Hébrard, J. (2001). Por uma bibliografia material das escritas ordinárias: o espaço gráfico do caderno escolar (França - séculos XIX-XX). Revista Brasileira de História da Educação, 1(1), $115-141$.

Le Goff, J. (2003). História e memória. Campinas: Unicamp.

Lima, S. P., \& Becalli, F. Z. (2018). Literatura infantil na alfabetização: apontamentos didáticometodológicos. Vitória: Edifes.

Macedo, R.T. (2018). Atividades de leitura de textos na alfabetização: problematizações a partir de cadernos escolares (Dissertação de Mestrado). Universidade Federal do Espírito Santo. Espírito Santo, Brasil.

Mignot, A. C. V. (2004). Cadernos escolares: um exercício de análise. Anais do I/ Seminário de Educação: Memória (s), História (s) e Educação: fios e desafios na formação de professores (pp. 83-90). São Gonçalo: UERJ.

Mignot, A. C. V. (2008). Cadernos à vista: escola, memória e cultura escrita. Rio de Janeiro: EdUERJ.

Mignot, A. C. V. (2008a). Escritas invisíveis: diários de professoras e estratégias de preservação da memória escolar. In A. C. V. Mignot and E. C. Souza (Org.s), Histórias de vida e formação de professores (pp. 99-116). Rio de Janeiro: Quartet: FAPERJ. 
Mignot, A. C. V. (2008b). Do primeiro rabisco até o be-a-bá. Catálogo da exposição "Não me esqueça num canto qualquer". III Congresso Internacional sobre Pesquisa (Auto)biográfica. Natal. set./2008.

Mignot, A. C. V. (2010). Janelas indiscretas: os cadernos escolares na historiografia da educação. In D. G. Vidal and C. M. Schwartz (Org.s), História das culturas escolares no Brasil (pp. 425446). Vitória: Edufes.

Mignot, A. C. V., \& Cunha, M. T. S. (2006). Razões para guardar: a escrita ordinária em arquivos de professores/as. Revista Educação em Questão 11(25), 40-61. Natal, Brasil.

Pinheiro, G. O. (2012). Práticas de alfabetização no município de Viana, no período de 2000 a 2009 (Dissertação de Mestrado). Universidade Federal do Espírito Santo. Espírito Santo, Brasil.

Ribeiro, C. O. F., \& Becalli F. Z. (2019). Enunciados sobre a alfabetização referendados na BNCC: palavras e contrapalavras. Vitória: Edifes.

Rizzo, J. S. M. O ensino das relações sons e letras e letras e sons no contexto da alfabetização no município de Vitória (Tese de Doutorado). Universidade Federal do Espírito Santo. Espírito Santo, Brasil.

Viñao, A. F. (2008). Os cadernos escolares como fonte histórica: aspectos metodológicos e historiográficos. In A. C. V. Mignot (Org.). Cadernos à vista: escola, memória e cultura escrita (pp. 15-33). Rio de Janeiro: EdUERJ.

\section{Notas biográficas}

Cleonara Maria Schwartz. Graduada em Letras-Português (1989) e Mestrado em Educação (1997) pela Ufes (1997), Doutorado em Educação (2004) e Pós-Doutorado (2012) pela Universidade de São Paulo, Brasil. Professora associada da UFES e Coordenadora do NEPALES. Tem experiência na área de Educação, com ênfase em Educação Escolar, atuando principalmente nos seguintes temas: educação básica, ensino superior, política educacional, alfabetização, ensino da leitura, literatura, história da educação, história do Espírito Santo.

Fabiana da Silva Kauark. Graduada em Pedagogia (2001) pela Universidade Estadual de Santa Cruz, Mestrado em Ciência de Educação (2008) pela Universidade Autônoma de Assuncion, Mestrado Ensino de Ciências e Matemática (2015) pelo Ifes, Doutorado em Educação (2011) pela Universidade Federal de Uberlândia e Pós-Doutorado pela Universidade de Aveiro (2018). Professora do IFES Campus Vila Velha e Coordenadora do FOPEC. Tem experiência na área de Educação, atuando principalmente nos seguintes temas: formação inicial e continuada de professores em espaços escolares e não-escolares, ensino e aprendizagem, metodologia científica, pensamento crítico.

Fernanda Zanetti Becalli. Graduada em Pedagogia (2001), Mestrado em Educação (2007), Doutorado em Educação (2013) com período sanduíche em Universidade do Estado do Rio de Janeiro, Pós-Doutorado (2019), ambos pela UFES. Professora do IFES Campus Vila Velha e Coordenadora do GEPALES. Tem experiência na área de Educação, com ênfase em Educação Escolar e interessa-se, principalmente, por estudos e pesquisas que possam contribuir para uma melhor compreensão das questões relacionadas com a alfabetização de crianças, a história da leitura e da escrita, a formação inicial e continuada de professores no contexto da Educação infantil e dos anos iniciais do Ensino Fundamental. 